\title{
Ohverdamine Kaama-tagustel udmurtidel
}

\section{Tatjana Minnijahmetova}

Kaama-tagusel alal (Bashkiiria loode- ja Permi oblasti Kujeda rajoonis) elab väike paganausuliste udmurtide grupp, kes tänini peab kinni igivanadest uskumustest, mida on mõjutanud formeeruvad maailmareligioonid. Käesolev artikkel on pühendatud Kaama-taguste udmurtide kombestikus levinud ohvritoomisviiside vaatlusele rituaalse käitumise kontekstis. Mõnedel juhtudel on osutatud ka teiste udmurdi etniliste ja etnograafiliste rühmade traditsioonilistele kommetele.

Ohverdamisel oli ja on täita tähtis osa pea kõigi udmurdi riituste juures, olgu need kollektiivsed või igapäevased, juhuslikud või erakorralised. Udmurdi etnograafia väljapaistev asjatundja N. G. Pervuhhin, kes on üksikasjaliselt kirjeldanud ohverdamist erinevatele jumalustele, märgib, et: ... nende [s.t udmurtide - T. M.] palvuste *1 põhiolemuse moodustab mitte niivõrd palvetamine, kuivõrd ohvri toomine (Pervuhhin 1888: 1). Samal arvamusel on ka tänapäeva teadlased (Vladõkin 1994; Hristoljubova 1984, 1995). Kõik udmurdi vaimse kultuuri uurijad on seda teemat otseselt või kaudselt puudutanud.

Kollektiivsed ohverdamised toimusid ja toimuvad tänini teatud kalendri-, perekondlikel ning hõimupühadel. Erakorralised kollektiivsed ohverdamised toimuvad küla või piirkonda tabanud suuremate õnnetuste puhul. Sõltumata rituaali liigist on igal neist oma korraldajad: ohvripapid ja abilised. Igal rituaalsel tegevusel on kindel koht ja ülesehitus. Oluline osa on perekondlikul ohvritalitustel, mis viiakse läbi peamiste tööde alustamisel ja lõpetamisel ning oluliste perekondlike sündmuste puhul. Individuaalseid ohvririitusi, millest sõltub mingis mõttes kogu ümbritseva maailma käekäik, võidakse toimetada vajaduse järgi iga päev ja kus tahes.

Kaama-taguste udmurtide ohvriannid võib jaotada kaheks: toidud ja esemed. Tänini on säilinud peaaegu kõik varasemate uurijate poolt kirjeldatud ohvriandide liigid. Siiski on kaasajal harvad hobuse- või veiseohvrid, kadunud on metslindude ohverdamine ja peaaegu jäägitult hõbemüntide annetamine. Kunagisi ohvriande asendavad odavad ja kõigile kättesaadavad asjad.

\section{Ohvritoidud}

Üldistavalt võib sellesse liiki kuuluvaid ohvriande nimetada udmurdikeelse sõnapaarigaga s'ion-juon (söök-jook, udm. s'iõnõ - sööma, juõnõ - jooma). Kõike söödavat tähistab mõiste $n^{\prime} a n^{\prime}$ (tänapäeva udmurdi keeles tähendab $n^{\prime} a n^{\prime}$ leiba), mis kätkeb endas nii sakraalset kui ka eetilist tähendust. Kui terminit $s^{\prime}$ ion-juon tajutatakse nagu tavalist toitu, siis $n^{\prime} a n^{\prime}$ väljendab lugupidamist; kuigi sõnade sisu on samane, ei kanna nad ühesugust semantilist tähendust.

Teraviljatoidud

Kesksed ohvritoidud valmistatakse töödeldud teraviljast. Kõigepealt kuuluvad siia hirsi-, nisu- ja kaeratangudest valmistatud pudrud $d z h u k$, samuti ka jahukissell - piz' shukkem. Ühispalvustel valmistatakse tihti segaputru, perekondlikel või hõimupalvustel ainult ühest tangusordist putru. Eelistatumad on hirsi- ja nisutangupudrud. Teraviljatoitude hulka kuulub ka leib n'an', mis on kõige polüfunktsionaalsem toit. Leiva olemasolu korral võib läbi viia iga ohvritalituse. Erilistes olukordades, kui muud võimalused puuduvad, kasutatakse leiba ilma tavapärase tseremooniaks ettevalmistuseta. Peale leiva on jahutoodetest kasutusel erilised hapud pannkoogid taban', hapendamata taignast pannkoogid mul'õm ja sitkest taignast rullitud ümmargused õhukesed pannkoogid kuar n'an'. 2ㅡ Riituse juures kasutatav kuar n'an' on sageli lihatäidisega. 


\section{Ohvrijoogid}

Kõikidel riitustel on udmurdidel olulised joogid. Muistsest aegadest peale kasutatakse nii oluliste kui ka vähetähtsate talituste juures õlut sur. Suvisel ajal kasutatakse vahel ka kodust kalja s'ukas'. Teise maailma elanikele annetatakse kodust alkohoolset jooki kumõshkat (puskarit A. L.) ja teed. Eriliseks maiustuseks peeti vanasti kanepiõli - kenem vöi. Kogu udmurtide asualal jäeti teatavate tööde lõpetamisel (teravilja- ja juurvilja koristamine, marjade ja puuviljade korjamine) mingi osa saagist kohahaldjale.

\section{Loomohvrid}

Loomi on udmurdid ohverdanud muistsest aegadest alates. Tänapäevalgi on sellel ohvril eriline osa. Suurte ohvriloomade arv ulatub mõnikord 60-ni, märkis eelmise sajandi uurija (Ostrovski 1874: 38). Eriti tähtsatel riitustel oli mõnede teadete kohaselt peamine ja kõige hädavajalikum pidustusese - luigepaar. Neid muretsetakse ka varakult ja mõnikord kalli hinnaga, 25 - 40 rubla eest. Kuni pidustuseni hoitakse neid luiki suures aus - toidetakse kõige maitsvamate roogadega. Mis osa on sellel linnul täita religioossel pidustusel, ma ei saanudki teada. ...Ohverdamiste lõpul viiakse luiged suure austusega, pidulikult ehitud kolmehobuserakendis Vjatka jõe äärde ja lastakse seal vabadusse, sidudes eelnevalt igaühele väikese hõberaha kaela. (Samas). Tänapäeval ei mäleta isegi vanad inimesed, et nad oleksid kunagi olnud sellise talituse osalised. $* 3$ Siiski on aastaringi ja elutsüklitega seotud riituste ja pidustuste juures tänini tähtsal kohal hane- ja pardiohvrid.

Arvatakse, et jumalad armastavad loomadest enim valget karva hobust, võiku varssa, aga ka lehmi ja lambaid. Eraldi oli jumalatele määratud loomade veri, sisikond ja luud. Silmapaistvalt palju ohverdati kanamune, ükski riitus ei toimunud ilma võita. Ohvrirooga oli tavaks valmistada ka piimaga.

\section{Ohverdamine kalendripühade ajal}

Kollektiivsed ohverdamised

Paljud kirjeldatud ohverdamised on säilinud tänini, kuigi igas piirkonnas võivad neil olla omad eripärasused. Peaaegu kõikjal on säilinud (või taastumas) pidulikud ühised palvused mör vös', bõddz'õm vös', óshtijak vös', el'en vös' jt. *4 Riituste eesmärk ja sisu ning läbiviimise aeg ei erine eelmiste sajandite traditsioonist. Veel 19. sajandil kirjutab N. Smirnov pärast külvitööde lõppu toimunud riitusest ja seal toodud annetest:"Gorbari *5 ajal, 29. juunil saavad jumalad vaid ohvriloomade verd, mis kallatakse maasse kaevatud aukudesse, ja luid, mis visatakse hõredasse metsatukka (Smirnov 1890: 228).

Kagu- udmurdid (Kaama-tagused - T. M.) korraldasid palvuse Bui jõel. Endise Ossinski maakonna Staraja Kõrga külas ohvriloomad vaheldusid: ühel aastal - raudjas varss, teisel - must härg (Jemeljanov 1921: 114).

I. Smirnovi teatel annetati Birski maakonnas busõ vös'il 트 kaks lammast: valge ja must (Smirnov 1890: 225).

Informantide andmetel ohverdati talvisel palvusel tol vös ${ }^{*} 7$ Bashkiirias Baltatshevo rajooni Shavjadõ külas vanasti aastane varss. Praegu ohverdatakse lammas/oinas või kaks hane, kusjuures lammas peab poeginud olema.

Palvust kuar vös'an (lehepalvus) ei esine igal pool. $\underline{\text { *8 }}$ Selleks puhuks valmistati piimaga puder, mis asetati metsalagendilul väiksesse auku. 
Tänapäeval ohverdatakse Bashkiirias Tatõshlõ rajoonis Aribashevo külas palvuse $d z^{\prime} e g$ busõlõ vös' (sõna-sõnalt palvus rukkipõllule) ajal maahaldjale (muzjem-kõlshin) must lammas, suure palvuse bõddz'ôm vös'i ajal taevahaldjale (in kõlshin) valge hani.

Sama rajooni Balzjuga külas ohverdatakse ühispalvusel mör vös' kolme liiki loomi ehk kuin'

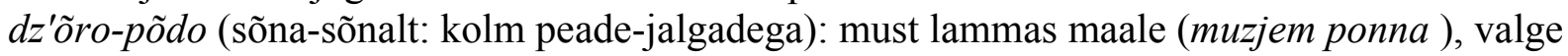
lammas valgele ilmale/ maailmale ( $d z^{\prime}$ ugõt dunne ponna), hani kõrgeimale jumalale Inmarile.

Palvusest kuarn'an' vös' võtavad osa ainult mehed, sõltumata vanusest, ning ohverdavad isaseid loomi: valge ja musta oina ning ühe isahane. Kodust võetakse kaasa sitkest taignast küpsetatud õhukesi pannkooke kuarn'an'.

Ekstreemsed ohverdamised

Nagu vanasti, nii viiakse ka praegu läbi riitusi, mis ei ole aegsasti ette planeeritud, vaid mille toimumise põhjuseks on ebasoodsad ilmastikutingimused või suured hädad ja õnnetused. Peale korraliste ohverdamiste leiavad aset ka erakorralised. Need on tingitud mingisugustest onnetustest: taudist, ikaldusest. Siis korraldatakse ühispalvusi (el'en vös'), millest võtab mõnikord osa mitukümmend küla; ohverdatakse lehmi, varssu, kirjutab Ufaa kubermangu Birski maakonna udmurdidest eelmise sajandi uurija (Smirnov 1890). Taolisi ohverdamisi korraldatakse ka tänapäeval, aga ohvriloomad on võrreldes eelmainitutega märksa väiksemad.

Perekondlikud ja hõimuohvrid

Minevikus ohverdati mitmesuguseid metslinde (eespool mainisime luiki). P. Pallas kirjeldab: Vissesko-Nunal (õigesti vös'as'kon nunal - palvepäev - T. M.) on enne heinategu ühes või mitmes tares sooritatava palvuse jaoks määratud päev, kusjuures hea ilma ja tööle kergenduse palumiseks ohverdatakse ja põletatakse lõkkes kirjurähn (ivesho), keda nad just selleks otstarbeks kinni pü̈̈dsid ja toitsid (Pallas 1788: 35). Muude metslinnuohvrite kohta vaata allpoolt.

Hõimu- ja perekaitsjate poole palvetati kõige sagedamini palvekojas kua/kuala. Seoses sellega, et paljudel ei ole praegu palvekodasid, viiakse talitusi läbi toa pühasenurgas, õues, aias, niidul või väikesel lagendikul metsas. Palvuse juurde kuuluvad kindlasti leib, või ja mesi.

Kirjeldades bõddz'õm akashka pidustusi endise Kaasani kubermangu Mamadõshi maakonna udmurtide juures, nimetab B. Gavrilov, et pärast palvetamist pannakse kualas vozhshudi (vozhshud - hõimu, perekonna kaitsja - T. M) $* 9$ riiulile leiba, kausikene meega ja okaspuu oksake (Gavrilov 1891). Riituse sisu pole tänini oluliselt muutunud.(Viimane lause tuleks ära jätta, kuna riituse sisule pole artiklis õrna vihjetki.)

Ohvrid koduhaldjatele

Palju pidustusi on pühendatud kodu- ja hoonehaldjatele. Sügisene ohverdamine mu kõlshinile oli arvatavasti määratud haldjale, kes hoolitses majapidamise eest. *10 G. Aptijev märgib ohverdamist kirjeldades, et peaaegu igal aastal ohverdati igas koduõues kas hani, lammas, härg või koguni varss. Ohvrilooma liha ei tohtinud süüa mitte keegi peale as näshilezlõ ,s.t omade, oma suguseltsi. Isegi mehele läinud tütrele oli see keelatud, sest teda arvati mehe hõimu hulka kuuluvaks. Samuti oli see keelatud naabritele*11 (Aptijev 1891: 120).

Samal eesmärgil korraldati tshuzh shun'õ vös'an (sõna-sõnalt: võigu hobuse ohverdamine), mis kordus, vastavalt vajadusele, mitme aasta tagant.

Rangelt järgitakse ohverdamist majahaldjale korka kuz'ole. Paljudes peredes teostatakse seda pärast uude majja kolimist, aga mõnikord korratakse rituaali igal aastal. Tatõshlõ rajooni Novõje Tatõshlõ ja Vjazovka külades on järgmine komme: keldris tapetakse must oinas 
gulbesh takale *12 ('keldri oinale') sõnadega: Gulbeshlõ dz'an s'otis'kom, korka kuz'olõ, dz'õrt kuz'olõ. Sõna-sõnalt: Keldrile anname elu (hinge), majahaldjale, majapidamise haldjale. Tavaliselt tapetakse loom samas, lihast keedetakse suppi, mida söövad ainult uude majja kolijad. Luud põletatakse ahjus. Janauli rajoonis Votjak Urada külas pannakse igal aastal keldrisse maja pühanurga alla valgesse rätikusse mähitud leivakannikas võiga. See on majahaldjatele korka kuz'o ja gulbesh taka.

Ohvrid ludile ja keremetile

Kaama-tagustel aladel on levinud palvetamine pühades hiites, mida nimetatakse kas lud või keremet. Erinevalt teistest haldjatest ja vaimudest, kellelt tuleb paluda head ja hüvesid, tuleb ludilt ja keremetilt paluda, et nad ei teeks inimestele ja loomadele kurja. Sellest on kirjutanud paljud möödunud sajandi, aga ka tänapäeva teadlased. Keremeti taraga piiratud nurka *13 tühjade kätega ei minda: ilmtingimata tuleb tuua midagi ohverdamiseks; isegi kui läheneb isa koos pojaga, siis ei piisa sellest, kui isal on ohver, vaid ka poeg peab viima kasvõi hane. Aga kui ta on koos isaga ja ilma ohvrita, siis ta peab seisma aias, ega tohi eraldatud nurka minna. Keremetile ohverdamised ja palvetamised toimuvad hilissügisel, Inmarile ja Kõldõsinile ainult pokrovini [suurmaarjapäevani], hiljem ei tohi nendele jumalatele ohverdada, sest "maa magab sellel ajal" (Potanin 1880-1882: 203).

Kõige varasem on P. Pallase kirjeldatud keremeti riitus: ...kõige suurema pidustuse - Keremet Nunal - viivad nad pidulike ohverdamistega läbi pärast lõikust ja kõigi põllutööde lõppu ohverdamispaigas ehk keremetis. Sealjuures ohverdatakse harilikult hobune, mis üldiselt peab olema raudjas. Kui sellist karva hobust pole ega muid peale ronkmusta, siis valitakse härg, lammas, hani ja part ja süüakse ära. Kõigepealt ohverdatakse väikeseid loomi ja lõpuks tona (tona, tuno - ennustaja, peamine korraldaja, preester - T. M) abiline tapab hobuse ja valmistab ta ette ohvrisöömingu jaoks. Suurem osa luid ja veri, ka rasvaga täidetud magu põletatakse, aga härja ja lamba pead koos kõigi hobuseluudega riputatakse kuuse otsa, mis kasvab keremetis. Nahkade koju toomine ja müümine on lubatud. (Pallas 1788: 35).

Tatõshlõ rajoonis keremete põroni (sõna-sõnalt Keremetile minek) palvusel ohverdatakse igas külas kolme liiki loomi: valge hani, valge ja must oinas. Palve ajal hoitakse käes karaskeid. Hapendatud või pärmitaignast küpsetisi ei tohi keremetile tuua.

Bashkiirias Burajevo rajoonis ütlevad Sarsazi küla elanikud keremetile hõbemünti $d z^{\prime} u g e s^{\prime}$ pannes: Kozma, Kõlshine, bereketde s'ot, tau Inmare-Kõlshine. Omin. (Issand, õnnista, anna kokkuhoidlikkust (arusaamatu, bereket tähendab murdes ometi küllust); tänan, minu InmarKõlshin. Aamen.) Janauli rajoonis Budzi Varjash külas küpsetatakse pühasse metsasallu ludi minekuks munapannkooke kuregpuz taban'. Eelnimetatud kommete elluviimisel jälgitakse rangelt, et ohvritoit ei satuks kanadele, koertele ja sigadele.

Ohvrid surnutele

Kummaline on kanade-kukkede roll ohvrilindudena. Erinevalt teistest linnu- ja loomaliikidest, pühendatakse neid ainult teise maailma või kurjadele vaimudele. Seda võib seletada sellega, et rahva ettekujutustes lind, kes siblib tahapoole (berlan' shabjas'ke on nendega seotud. *14 Nii kevadiste, kui ka sügiseste ühispeiete ajal on kombeks ohverdada kana või kukk ja keeta neist ja tangudest supp. Sellist suppi nimetatakse pös' shõd ('kuum supp').

Bashkiirias Kaltassinki rajooni Bolshoi Katshaki külas ohverdatakse peiete ajal kana või kukk, keedetakse temast suppi, surnutele valatakse leent kaussi, kuhu pannakse ohvrilinnu pea ja rituaalset küpsetist. See kõik viiakse õue, põhja poole. 
Erinevalt teistest ohvriroogadest, tuleb peietoitu anda koertele ja lindudele. Peietel keedetakse putru, küpsetatakse pannkooke ning pannud need oma taredes kaussidega lauale, seatakse ja süüdatakse pudru ümber kuus vahakü̈̈nalt, kutsutakse oma usu kombel jumalat appiàKui küünlad ära põlevad, siis viskavad nad pudru peale lauale asetatud pannkoogid koertele, ning pärast küünalde kustumist viskavad kogu selle pudru ja lauale jäänud pannkoogid koertele ... (Rõtshkov 1887: 132-133). Selline komme on tänapäevalgi üldlevinud. Mälestuspäeval minnakse vastu päeva minnes surnuaeda, sugulaste hauadele visatakse rituaalset toitu, valatakse alkoholi ja teed.

Tuleb märkida, et kommet jätta laua peale ohvriroogasid, mis on mõeldud teispoolsetele, nimetatakse puktis'kon (udm puktis'kõnõ - 'välja panema', 'lauda katma'); surnute "kostitamist" surnuaias *15 nimetatakse kujas'kon (udm kujas'kõnõ - 'viskama'). Loomade ja toiduainete ohverdamist jumalatele ja vaimudele nimetatakse vös'an (udm vös'anó - 'ohverdama', 'pühitsema').

Surnud esivanematega on seotud veel haruldane komme jõr-põd s'oton (sõna-sõnalt: pea ja jalgade kinkimine). Aasta (või rohkem) pärast vanemate surma ohverdab tütar emale lehma, poeg isale hobuse. Pärast riitust viiakse ohvrilooma pea- ja jalaluud metsa või pühasse metsasallu ja riputatakse puude otsa.

Vanasti oli levinud musta kana rituaalne tapmine, et vabaneda igasugustest haigustest. Mõnikord tapeti taliviljapõllul kukk, kaevati pea ja jalad masse, et ta nokiks usse (Gavrilov 1891). Tänapäeval on see komme haruldane. Tavatu on koera või kutsika tapmine loomataudi ajal. Sellise õnnetuste ajal teevad noored karjas (ölet) lõket, hõõrudes üht puutükki teise vastu. Koer raiutatakse pooleks, põletatakse, maa peale tõmmatakse sümboolne joon, millest aetakse hiljem loomi üle (Aribashi küla Tatõshlõ rajoonis).

\section{Ohvriesemed}

Teise suure ohvriandide liigi moodustavad erinevad esemed. Kõige hinnalisem ohvriand on raha. Tänapäevani on säilinud komme panna maha hõbemünte $d z^{\prime} u g e s h^{\prime}$ keremetile. Keremetile pühendatud hiide sisenedes või juhul, kui keegi tahab seal heina niita, jätab ta luba paludes maha mündi. Vanasti jäeti palvuste ajal raha rituaalse puu alla või selle õõnde.

Veehaldjale vukuz'ole visatakse vette münt (võib ka leiba) üle jõe minnes. Kui pruut läheb pulmapäeval allikast vett tooma, siis lunastab ta enda haldjalt hõbemündiga välja. Vetehaldjatele visatakse kivikesi, taimi ja puust esemeid. Näiteks enne ujumist lastakse vette mõni eelmainitud esemetest, öeldes seejuures: Mone en kut, tae kut! (Ära võta mind, võta see (nimetatakse ese)!). Haigustest ja tõvedest püütakse vabaneda, riputades rätikuid, linikuid ja kangatükikesi allikate juurde.

Nahahaigusi seostatakse sellega, et inimene kas nuuskas nina või sülitas vette või lihtsalt sõimas teda, mispeale «vesi võttis ta kinni». Tervenemiseks visati posija õpetuste järgi jõkke või allikasse linasesse riidetükki seotud kruubid ja sool (Aptijev 1892: 120). Baltatshevo rajooni èavjadõ külas visatakse, juhul kui haigust seostatakse veehaldjaga (vukuz'o), vette hirsitangusid ja öeldakse: Vu ke kutem, med lez'oz, intaje med kutoz (Kui vesi püüdis kinni, lasku lahti, võtku see!).

Veehaldjale ohverdamine toimus kevadise tulvavee ajal. Bui udmurdid ohverdasid veele hane või pardi sügisel, enne jääkaanetust.

Äkiliste haiguste puhul, kui arvati, et kuala kutem - Kuala vaim püüdis kinni, riputati pühakoja nurka riidetükikesi või torgati seina sisse kaseoks, mille külge oli seotud väikesi riidetükke. Mõnel pool ohverdati sellistel juhtudel teder - tur (Janauli rajooni Starõi Varjashi küla). 
Kui keegi komistas või kogemata kukkus ja vigastas seejuures jäsemeid või jäi haigeks, siis arvati, et ta sattus maakuradi peale. Et teda meelitada, peideti hämaral ajal mulda leivakannikas koos munaga (Aptiev 1892: 119-120).

Teeleminekuohvrid

Palju on üles tähendatud traditsioonilisi kombeid, mida toimetati enne teekäiku või mis olid seotud teeleminekuga. Huvitavat kommet on kirjeldanud Starõi Varjashi kooliõpetaja G. Aptiev: Kui õues on leivapätsiga palvetatud, lõigatakse see tükkideks ning pärast seda, kui kogu pere on leivast $s^{\div} \div$nud, võtab teeleasuja ühe viilu ja paneb põue. Sõitnud läbi küla, võtab ta palveleiva viilu põuest ja viskab hobust peatamata väikeste tükkidena kahele poole, $\div$ eldes seejuures: "miele s'iele erõshisd'os, mon s'öram erõshõsa en vetlele, valelõ no, aslõm no kaptilok karele", s.t sö̈ge paharetid, ärge tulge mu järele, ärge vaevake ei mind ega minu hobust (Aptiev 1892: 119). Taoliste kommete järgimine on siiani üldtuntud: armeesse saatmisel viskab noorsõdur läbi küla või üle silla sõites leivaviile kahele poole teed või vette; iga teeleasuja, ükskõik kuhu ta läheb, võtab endaga leivaviilu kaasa.

Ohvrid endisele kodupaigale

Siiani on säilinud kombed, mis on pühendatud nende alade kohahaldjatele, kust udmurdid emigreerusid Kaamatagustele aladele. $s^{\prime} \ddot{o} r$ s'õrs (tagatee) rituaal toimub iga kuue aasta tagant. Must härg ohverdatakse kohas nimega t'eber kõr ('ilus lagendik metsas'). Selle ohverdamisega palutakse selle koha haigusehaldjaid, kust saabusid nende vaarisad, et nad ei tuleks uude kodukanti, nüüdsesse elupaika ega teeks neile kahju (Aptiev 1891: 17-18). Taolist komme on tänini säilinud Kaltassinki rajooni udmurtidel.

Aptiev kirjeldas ka mör s'ôrsi (haiguste tee) rituaali. Igal aastal vil' tõli ('uus tuli') ajal ohverdatakse südaööl must kits (s'öt kes'taka) ja palutakse endise kodukandi haigusehaldjaid, et nad ei tuleks koduloomade kallale (Aptiev 1891: 18).

\section{Kokkuvõte}

Vaadeldes erinevaid ohvriandide liike Kaama-taguste udmurtide kombestikus võime neid funktsiooni alusel klassifitseerida. Eespool toodud näidetest nähtub, et toiduaineid ohverdatakse põhiliselt positiivsetele jumalatele ja haldjatele, esemeid neile, kellesse suhtutakse negatiivselt. Mõlemat liiki üleloomulikud olendid võivad ümbruskonnale mõjuda nii positiivselt, kui ka negatiivselt.

Erinevatele jumalatele ja haldjatele ohverdatavatel toiduainetel ja esemetel on ka palju teisi funktsioone, kuid antud juhul on esitatud tähendused, mis neil on ohvriannina.

\section{Kirjandus}

Aptiev, G. 1891. Iz religioznõh obõtshajev Votjakov Birskogo ujezda Ufimskoi gubernii. IOAIE. T. X, võp. 3. Kasan.

Aptiev G. 1892. Religioznõe obõtshai i poverija votjakov Birskogo ujezda Ufimskoi gubernii. IOAIE. Kasan. T.X, võp. I, lk 119-120.

Gavrilov, B. 1891. Poverja, obrjadõ i obõtshai votjakov Mamadõshskogo ujezda Urjas-Utshinskogo prihoda. Trudõ IV arheologitsheskogo sjezda v Rossii. T. II. Kasan.

Holmberg, U. 1914. Permalaisten uskonto. Suomensuvun uskonnot IV. Porvoo.

Hristoljubova, L. 1995. Kalõk sh'amjestõ tshaklasa (Udmurtskie narodnõje obõtsai). Izhevsk. Jemeljanov A.1921. Kurs po etnografii votjakov: Ostatki starinnõh verovanii i obrjadov u votjakov. Võp. 3. Kasan. 
Lintrop, A. 1993. Udmurdi rahvausundi piirjooni. Tartu.

Ostrovski, D. 1874. Votjaki Kazanskoi gubernii. Trudõ OEIKU. T. IV, nr. 1. Kasan.

Pallas, P. 1788. Puteshestvije po raznõm provintsijam Rossijskoi imperii. Tshast III. S. Peterburg.

Pervuhhin, N. 1888. Eskizõ predanii i bõta inorodtsev Glazovskogo ujezda. Eskiz II. Vjatka.

Potanin, G. 1880-1882. U votjakov Jelabuzhskogo ujezda. IOAIE. T. III. Kasan.

Smirnov, I. 1890. Votjaki. IOAIE. T. VIII, võp. 2. Kasan.

Topografija Orenburgskoi gubernii. Sotshinenija P. I. Rõtshkova 1762 goda. Orenburg 1887.

Vereshtshagin G. E. 1995. Sobranije sotshinenii. Tom pervõi. Votjaki Sosnovskogo kraja. Izhevsk

Vladõkin, V. 1994. Religiozno mifologitsheskaja kartina udmurtov. Izhevsk.

\section{Aado Lintropi kommentaarid}

* 1 Nii udmurdid kui nende usundi uurijad on ohverdamisega seotud rituaalsete toimingute tähistamiseks kasutatud udmurdi sõnad vös', ja vös'as'kon vene keelde tõlkinud sõnaga molenije - palvus. Tegelikult ongi ohvritoomine tihedalt palvetamisega seotud: enne iga söögi või joogi ohverdamist pöördutakse palvega jumalate poole, samuti toimitakse ka enne ohvrilooma veristamist. Palvetatakse kultusepaigale jõudes või enne hiide sisenemist, palvetatakse ka sealt lahkudes. Võib küll öelda, et ohver on palvuse tuum, kuid see tuum on palvetega ümbritsetud.

* 2 sõnasõnalt leheleib.

* 3 Pole kindel, kas selline luikede austamise komme üldse laiemalt levinud on. Tsiteerivad ju kõik teadlased just sedasama Ostrovskilt pärinevat kirjeldust. Lisaks temale on luikede kultusest kirjutanud N. Afanasjev.

* 4 mer (vrd. vene mir) tähistas udmurtidel vanasti külakogukonda, omadussõnana ka 'ühis-, ühine'; el' - 'piirkond, maa, kogukond'; bõddz'õm - 'suur'.

* 5 gerber - palvus pärast kevadkülvi, langeb kokku peetripäevaga (12. juuli uue kalendri järgi).

* 6 busõ võs' - sõnasõnalt põllupalvus. Vladõkin toob ära mitu erinevat teadet sellenimelise palvuse kohta: a) sama, mis gershõd (pärast kevadiste põllutööde lõppu), b) küla ühispalvus peale kevadkülvi, c) palvus üks nädal enne nelipühi, d) palvus nelipühade ajal (Vladõkin 1994: 239).

* 7 Vereshtshagini järgi pidasid praeguse Đarkani rajooni alal elanud udmurdid sellenimelist püha esimesel jõulupühal (Vereshtshagin 1995: 63), Vladõkinil kannab samale päevale märgitud püha nimetust tolsur - talveõlu (Vladõkin 1994: 226). Sellega algas ühtaegu talvise pööripäeva ja jõulude periood vozho dõr. Glazovi maakonna udmurtidel kandis sama püha nimetust vozho shõd s'ion - vozho supi söömine (Pervuhhin 1888: 125, 135).

* 8 Pervuhhini teatel tähistasid Glazovi maakonna udmurdid sellenimelist püha esimesel nelipühal (Pervuhhin 1888: 65).

* 9 Tegemist on sugukonna ja perekonna kaitsehaldja vorshudiga, kelle nimetus tuleneb sõnadest vordõnõ - 'kasvatama, hoidma, sisaldama' ja shud - 'õnn'.

* 10 Majahaldjat korka kuz'o/võzhul kuz'o/jurt kuz'o ja maahaldjat mu-kõlèini ühendab eelkõige ohvritoomisviiside sarnasus - ka majahaldjale ohverdatakse sageli maasse kaevatud auku. 
* 11 Ka tänapäevani korraldataval gershõdi nime kandval palvustetsüklil Varklet-Bodjas tohivad maahaldjale pühendatud palvusel osaleda ja ohvritoite süüa vaid oma küla elanikud. Teistel palvuspäevadel see keeld ei kehti.

* 12 gulbeè taka on udmurtidel üldiselt majahaldjale toodava ohvri nimetusi. Vereshtshaginil näiteks kannab vastav riitus nimetust gulbeèe taka vös'an - keldris oina ohverdamine (Vereshtshagin 1995: 70). Ka U. Harva nimetab vastavat ohvrit majahaldjale gulbeè taka. (Holmberg 1914: 146). Bashkiirias on sellest kujunenud majahaldja sünonüüm.

* 13 Silmas on peetud ohvrihiie muust osast eraldatud ning kõige pühamaks peetud paika, kuhu mõnel pool ei tohtinud minna keegi peale hiiepapi ja ta abiliste. Udmurdi sõnad lud (väli, liitsõnades ka tähendusega mets-, näit. lud pars' - 'metssiga' või keremet (laen volgabulgaaria ajast, vrd. ka türgi keramet 'ime', kerem 'suuremeelne, armuline, üllas') tähistavad harilikult kultusepaika, mis on ümbritsevast eraldatud taraga. Siseneda võivad ainult mehed. Tara sees on veel teine tara, mis eraldab muust hiiest kõige pühama osa. Vt. Lintrop 1993: 50.

* 14 Meie jaoks veidi kummalisena kõlav selgitus, kuid udmurtidel üldiselt aktsepteeritud, mistõttu seda peetakse piisavaks põhjendama, miks neid linde võib ainult surnutele ohverdada.

* 15 Kujas'koniks nimetatakse mõnel pool surnute mälestamist mujalgi kui surnuaias (Varklet-Bodjas näiteks). 